\title{
Allogeneic Haematopoietic Cell Transplantation for Myelofibrosis: Proposed Definitions and Management Strategies for Graft Failure, Poor Graft Function and Relapse: Best Practice Recommendations of the EBMT Chronic Malignancies Working Party
}

Donal P McLornan ${ }^{1}$, Juan Carlos Hernandez Boluda ${ }^{2}$, Tomasz Czerw³ ${ }^{3}$ Nicholas Cross ${ }^{4}$, H. Joachim Deeg ${ }^{5}$ Marcus Ditschkowski ${ }^{6}$, Mufaddal T Moonim ${ }^{7}$, Nicola Polverelli ${ }^{8}$, Marie Robin ${ }^{9}$, Mahmoud Aljurf $^{10}$, Eibhlin Conneally ${ }^{11}$ Patrick Hayden ${ }^{11}$, Ibrahim Yakoub-Agha ${ }^{12}$.

1. Department of Haematology, Guy's and St.Thomas' NHS Foundation Trust and University College Hospitals, London, UK

2. Hospital Clinico Universitario, Valencia, Spain

3. Maria Sklodowska-Curie Institute, Gliwice, Poland

4. National Genetics Reference Laboratory (Wessex), Salisbury District Hospital, Salisbury, UK

5. Fred Hutchinson Cancer Research Center and the University of Washington, Seattle, Washington, USA

6. Department for Bone Marrow Transplantation, University of Essen, Essen, Germany

7. Department of Histopathology, Imperial College Healthcare NHS Trust, London

8. Unit of Blood Diseases and Stem Cell Transplantation, Dpt. of Clinical and Experimental Sciences - University of Brescia, ASST Spedali Civili, Brescia, Italy

9. Hopital Saint-Louis, APHP, Université de Paris, Paris, France

10. Oncology Center, King Faisal Specialist Hospital \& Research Center, Riyadh, Saudi Arabia

11. Haematology Department, St James Hospital, Dublin, Ireland

12. CHU de Lille, Univ Lille, INSERM U1286, Infinite, 59000 Lille, France

\section{Corresponding authors :}

Dr. Donal McLornan Professor Ibrahim Yakoub-Agha

Haematology Department Maladies du Sang, CHU de Lille

Guys Hospital, London, UK INSERM, U1286, Lille, France

Email: donal.mclornan@nhs.net ibrahim.yakoubagha@chru-lille.fr

Telephone: +44 $2071881431 \quad$ +33 (0) 3.20.44.55.51

\section{Word Count: 5811}

Competing Interests: none of the authors have any competing interests for this work and nor were any grants obtained towards its completion. 


\section{Abstract}

Allogeneic Haematopoietic Cell Transplantation (allo-HCT) remains the only curative approach in Myelofibrosis (MF). Despite advances over recent decades, relapse and non-relapse mortality rates remain significant. Relapse rates vary between $15 \%$ and $25 \%$ across retrospective studies and management strategies vary widely, ranging from palliation to adoptive immunotherapy and, in some cases, a second allo-HCT. Moreover, in allo-HCT, there is a higher incidence of poor graft function and graft failure due to splenomegaly and a hostile 'pro-inflammatory' marrow niche. The Practice Harmonisation and Guidelines subcommittee of the Chronic Malignancies Working Party (CMWP) of EBMT convened an international panel consisting of transplant haematologists, histopathologists and molecular biologists to propose practical, clinically relevant definitions of graft failure, poor graft function and relapse as well as management strategies following allo-HCT. A systematic approach to molecular monitoring, histopathological assessment and chimerism testing is proposed. These proposed recommendations aim to increase the accuracy and uniformity of reporting and to thereby facilitate the development of more consistent approaches to these challenging issues. In addition, we propose management strategies for these complications. 


\section{Introduction}

Despite many therapeutic advances in the field of Myelofibrosis (MF) over the last decade, allogeneic haematopoietic cell transplantation (allo-HCT) remains the only potentially curative option(1). Registry data reveal an increase in MF allo-HCT activity, with an increasing number of older recipients, the use of reduced intensity conditioning (RIC) and more mismatched donors over time. Current EBMT-European LeukemiaNet (ELN) criteria, last revised in 2015, suggest that 'All patients with intermediate-2 or high-risk disease according to IPSS, DIPSS or DIPSS+, and age $<70$ years, should be considered potential candidates for allo-SCT'(2). Moreover, patients less than 65 years of age with intermediate risk-1 disease 'should be considered candidates for allo-HCT if they present with either refractory, transfusion-dependent anaemia or peripheral blood blasts $>2 \%$, or adverse cytogenetics (as defined by the DIPSS+ classification).' The post allo-HCT course can be complex due to a 'hostile', fibrotic, pro-inflammatory marrow niche, bulky splenomegaly and a higher incidence of poor graft function (PGF)(1). Moreover, despite improving outcomes over time, relapse and non-relapse mortality remain significant. Relapse rates can range from $15-25 \%$ and approaches to relapse management vary greatly (3-5).

In MF allo-HCT, clearly defining relapse is made difficult by the dynamics of donor: recipient chimerism, variable rates of molecular disease clearance (when a marker of measurable residual disease (MRD) is available) and widely varying rates of resolution of marrow fibrosis and splenomegaly. We recently performed a survey of 36 international allo-HCT centres with experience in this area in order to get a 'snapshot' of current practice in MF allo-HCT (4). This revealed marked variation in practice relating to disease assessment both pre- and post- allo-HCT, monitoring (bone marrow trephines, chimerism, molecular and cytogenetic annotation) and in the definitions and management of relapse. It highlighted the need for best practice guidelines for the transplant community focused on a working definition of relapse following allo-HCT and on clarifying the difference between graft failure (GF), PGF and relapse. Moreover, there is a need for practical 
management recommendations. These guidelines are the first in a series focused on MF allo-HCT with the aim of providing practical, clinically relevant consensus criteria for defining and managing GF, PGF and relapse. 


\section{Methodology}

The Practice Harmonisation and Guidelines subcommittee of the Chronic Malignancies Working party of EBMT proposed this workshop in January 2020. A survey of 36 international allo-HCT centres with experience in this area was performed, highlighting wide variation in clinical practice (4). A panel of international experts in the field of MF allo-HCT, molecular biology and histopathology was convened. The objective of the panel was to identify the key practical issues relating to GF, PGF and relapse following MF allo-HCT and to produce best practice consensus guidelines. Relevant literature in the MEDLINE and PubMed databases was reviewed by pairs of experts who generated summative conclusions for review by the group. Two teleconferences were held in May 2020 to discuss and refine the suggested recommendations. Given the absence of evidence from randomised trials, the decision was made not to grade these recommendations. They therefore represent the consensus views of the authors. 


\section{Definitions}

\section{Engraftment}

Engraftment after allo-HCT is defined as an absolute neutrophil count (ANC) greater than $0.5 \times 10^{9} / \mathrm{L}$ for three consecutive days. Platelet recovery by definition requires a platelet count $>20 \times 10^{9} / \mathrm{L}$ for seven consecutive days free of transfusion support. A haemoglobin $(\mathrm{Hb})>80 \mathrm{~g} / \mathrm{L}$, without support, is also necessary to meet the criteria for complete engraftment $(6,7)$.

\section{Post-transplant cytopaenias}

Mono-, bi- or pancytopaenia can occur after allo-HCT in MF patients and can be mild, moderate or severe (i.e. ANC $<0.5 \times 10^{9} /$, anaemia requiring transfusion and/or platelet count $<20 \times 10^{9} / \mathrm{L}$ ). In contrast to cytopaenias that are related to GF, PGF or MF relapse, cytopaenias related to other causes (drug toxicities, vitamin deficiency, viral infections, GVHD, macrophage activating syndrome, hormonal disorders) are usually transient.

\section{Graft Failure}

Post-transplant GF can lead to significant morbidity and mortality, and early recognition is key (8). In a recent EBMT study, the five-year survival rate in patients who developed graft failure was $14 \%$ (9). In addition to recognised donor-, conditioning- and cell-dose-related risk factors for GF in allo$\mathrm{HCT}$, there are particular risks associated with MF allo-HCT including the presence of often bulky splenomegaly, an adverse marrow 'microenvironment' due to fibrosis, chronic inflammation, iron overload and potential HLA-sensitisation if the recipient has been heavily transfused $(1,10)$. Of note, Keyzner et al found a higher risk of GF in patients undergoing allo-HCT utilizing HLA mismatched donors compared to matched donors (60\% versus $13 \%, p=0.04)$, whereas the bone marrow (BM) fibrosis grade and degree of baseline splenomegaly were not found to affect GF rates (11). GF can be divided into primary GF or secondary GF based on current EBMT definitions (10). Primary GF is defined by an ANC $<0.5 \times 10^{9} / \mathrm{L}$ by day +28 following stem cell infusion, haemoglobin $<80 \mathrm{~g} / \mathrm{L}$ and platelets $<20 \times 10^{9} / \mathrm{L}$. The EBMT guidelines recommend that, in the context of a RIC 
allo-HCT, evaluation of donor cell chimerism is required. In cord blood transplantation, where there is a higher incidence of delayed engraftment/ recovery kinetics, count recovery up to day +42 is permitted before the criteria for primary GF apply.

Secondary GF frequently represents a heterogeneous group in 'real world' practice. It is currently defined by EBMT criteria as the presence of an ANC $<0.5 \times 10^{9} / \mathrm{L}$ occurring after initial engraftment and not related to relapse, infection, or drug toxicity. In the RIC setting, loss of donor haematopoiesis (frequently defined by $\%$ donor CD15/CD33 population) to below $5 \%$ is required, although the use of this threshold is controversial.

\section{Poor graft function}

There is no universally accepted definition of PGF. The current EBMT definition requires the occurrence of two or three cytopaenias lasting for more than two weeks, after day +28 in the presence of donor chimerism $>5 \%$ (10). However, this definition is difficult to apply in clinical practice given chimerism kinetics and potential overlap with evolving graft failure. It is our view that the definitions suggested by both Stasia et al and Klyuchnikov et al offer a more practical and discriminating set of criteria $(12,13)$. Here, PGF is defined by the presence of mild/moderate cytopaenias in at least two haematopoietic lines (ANC $\leqslant 1.5 \times 10^{9} / \mathrm{L}$, platelet count $\leqslant 30 \times 10^{9} / \mathrm{L}, \mathrm{Hb} \leqslant 85 \mathrm{~g} / \mathrm{L}$ ) lasting for more than two consecutive weeks following documented engraftment, beyond day +14 and in the presence of full donor chimerism. Cytopaenias are frequently accompanied by a hypocellular bone marrow although this is not always the case. This definition mandates the absence of severe acute or chronic GVHD, relapse, and either drug- or CMV reactivation-related myelosuppression. Suggested risk factors include underlying host (age)- and disease-related characteristics (higher risk with MF), the use of unrelated donors, major ABO incompatibility, prior HLA sensitisation and low CD34+ cell doses (1416). The Hamburg group reported on the incidence and risk factors for PGF in a single centre study of 100 patients with MF who underwent RIC allo-HCT, predominantly conditioned with either busulphanor treosulphan- based regimens and in the pre-ruxolitinib era (14). The cumulative incidence of PGF 
was $17 \%$ with a median time of onset of 49 (range, 4-99) days. Risk factors within this cohort included older age, particularly in males, and the persistence of bulky splenomegaly at day +30 .

\section{MF Relapse following allo-HCT: suggested categorisation}

The current International Working Group for MPN Research and Treatment (IWG MRT) criteria for response in MF in the non-allo-HCT setting were last revised in 2013 (17). These encompass not only morphological and haematological criteria for complete remission (CR) and partial remission (PR) but also clinical improvements, anaemia, spleen and symptom responses, where relevant, alongside cytogenetic and molecular evaluation (Table 1). These criteria have not been validated in the post alloHCT setting; direct applicability would be difficult and clearly would not take account of chimerism and variable resolution of fibrosis and splenomegaly.

In the non-transplant setting, the definition of $C R$ in MF includes normal age-adjusted marrow cellularity on the trephine biopsy, $<5 \%$ blasts and $\leq$ grade $1 \mathrm{MF}$ according to the European grading system (currently the WHO Fibrosis score)(18). Accompanying peripheral blood count criteria include $\mathrm{Hb} \geq 100 \mathrm{~g} / \mathrm{L}$ as well as being below the defined local upper normal limit (UNL), ANC $\geq 1.0 \times 10^{9} / \mathrm{L}$ and $<U N L$, and platelets $\geq 100 \times 10^{9} / \mathrm{L}$ and $<$ UNL with $<2 \%$ immature myeloid cells on the blood smear $(<5 \%$ immature myeloid cells in splenectomised patients). Finally, clinical criteria include resolution of clinical symptoms, no palpable spleen or liver and no evidence of extramedullary haematopoiesis $(E M H)$, albeit in real world practice this is difficult to ascertain. One potentially controversial point included in the non-transplant setting discussed above is resolution of the fibrosis to $\leq$ grade $1 \mathrm{MF}$. The dynamics of fibrosis resolution is often very heterogeneous and only occurs in a proportion of patients undergoing drug therapy where duration of response in this regard, if any, remains unpredictable. 
A practical approach to defining relapse following allo-HCT would be to further categorise it as one of the following: (1) molecular relapse only, (2) cytogenetic relapse only (rarely reported), (3) molecular AND cytogenetic relapse only, and (4) morphological/clinical relapse. Changes in chimerism would also clearly need to be considered.

\section{Defining Morphological Relapse}

In our view, the presence of stable marrow fibrosis, at least within the first twelve months, although of potential concern with increasing time from transplant, is in itself insufficient to diagnose MF relapse. Its significance requires correlation with concurrent clinical findings as well as haematological, MRD and chimerism results. With emerging or established relapse, 'typical' MF-related findings such as age-adjusted hypercellularity, megakaryocytic abnormalities and sustained increases or persistence of marrow fibrosis become more prominent. For the purposes of a new definition of relapse, two posttransplant morphological scenarios should be considered: (1) relapsed disease (recurrence of myelofibrotic morphology and an increased grade of fibrosis following confirmed normalization of marrow / regression of fibrosis), and (2) progressive/accelerated disease (development of myelodysplasia, monocytosis or increased blasts).

The morphologic criteria for post-transplant relapse require that regression of myelofibrotic features had been confirmed previously. In the presence of such normalization of morphology and an associated documented reduction in fibrosis post-allo-HCT, the criteria for relapse include:

1. Increase in age-adjusted cellularity and abnormal M: E ratio

2. Megakaryocytic abnormalities typical of MF (pleomorphism, hyperchromasia, cloud-like nuclei, and megakaryocytic clusters)

3. Increase in grade of reticulin/collagen fibrosis (it should be borne in mind that the previously formed new bone usually takes a long time to be resorbed/resolved and that this should not therefore be used in grading post-transplant unless its density is significantly 
greater than the pre-transplant biopsy or there is active evidence of continuing new bone deposition)

The scenarios of progressive or accelerated disease post-transplant can be considered under the following categories:

1. Evidence of myelodysplasia (usual criteria for erythroid \& myeloid lineages ensuring that therapy-related changes are excluded; presence of small hypolobated megakaryocytes / micromegakaryocytes for megakaryocytic lineage)

2. MF-related monocytosis that is persistent and not attributable to other causes

3. Increasing peripheral blood / bone marrow blast counts

4. Acute myeloid leukaemia

\section{Defining Molecular Persistence and Relapse}

The definition of molecular persistence and relapse in MF allo-HCT is complicated by the variable kinetics of clearance of detectable MRD. It is not feasible to assign an arbitrary time frame to define molecular persistence. However, persistent detectable disease at 3-6 months post-transplant suggests that the patient is at a higher risk of frank clinical relapse. We suggest that molecular relapse could be defined as the re-appearance of the established MRD marker (on two consecutive peripheral blood (PB) samples at least 28 days apart) after documented clearance which had also been confirmed by two consecutive negative PB samples collected at least 28 days apart.

\section{Defining Cytogenetic relapse}

Cytogenetic abnormalities are detected in up to $45 \%$ of patients with MF, dependent on the risk group and the testing methodology(19). Cytogenetic monitoring following MF allo-HCT is frequently performed using either standard Giemsa-banded (G-banded) karyotyping, FISH for any previously 
detected anomaly or SNP Arrays. Cytogenetic relapse can be defined as detection of an informative, previously detected chromosomal abnormality on G-banded, FISH or SNP Array analysis in a patient not meeting the criteria for morphological relapse, as described below. Of note the prognostic significance of cytogenetic evolution post MF- allo-HCT has not been defined.

\section{Defining relapse by Chimerism Analysis after MF allo-HCT}

It is well established in allo-HCT practice that rising mixed chimerism (MC) in myeloid malignancies is, in general, associated with an increased risk of relapse. Recent studies have evaluated the effects of mixed chimerism on relapse risk $(20,21)$. Srour et al reported on the value of mixed myeloid chimerism (MMC) in predicting early relapse, defined as $<95 \%$ donor myeloid chimerism at any stage after day $+30(21)$. A total of 35/82 MF allo-HCT patients had MMC, 29 of whom had previous full donor chimerism. Only one patient who maintained full donor chimerism experienced disease progression. In contrast, all apart from two patients with MMC had evidence of morphological or molecular relapse at the time of detection of MMC or soon after. Of note, the majority had detectable molecular relapse concurrent with MMC and, in a few patients, MCC preceded molecular relapse. The four-year progression-free survival (PFS) in the MMC cohort was $4 \%$ versus $60 \%$ in those with full donor myeloid chimerism $(p<0.0001)$. More recently, Deeg et al found that mixed CD33+ chimerism was associated with worse OS and RFS and higher rates of relapse, irrespective of the CD34+ dose infused. Interestingly, in this series, mixed CD3 chimerism was associated with improved RFS and lower rates of GVHD. There was no association between mixed CD3 chimerism and graft failure (22). Although the kinetics of chimerism following the varying range of conditioning platforms used in MF allo-HCT are not fully understood, serial analysis at fixed time points is pivotal for monitoring engraftment, and better defining graft failure facilitates a clearer definition of relapse. Some patients with apparent mixed chimerism remain in long term 'remission' following allo-HCT for MF. 


\section{Post-transplant monitoring}

\section{Morphological Assessment}

Comprehensive, large scale reports of serial marrow morphology and fibrosis remodelling after alloHCT in MF are lacking, as a result of which it is difficult to make conclusive recommendations regarding the differences between response and relapse. Markedly varied dynamics in the resolution of typical MF features following allo-HCT are likely dependent on disease stage, conditioning intensity, the achievement of sustained engraftment and the extent of donor chimerism. In our experience, post MF allo-HCT marrow samples frequently demonstrate reduced age-adjusted cellularity, particularly in older recipients. Discrepant aspirate and trephine findings are not uncommon, particularly early post allo-HCT. A further challenge is that the distribution and grade of marrow fibrosis can be heterogeneous, making direct comparisons with the pre-allo-HCT trephines challenging (23).

Tamari and colleagues elegantly summarised findings from various studies comparing pre- and postallo-HCT marrow characteristics (24). MF-associated hypercellularity resolves in the vast majority of cases and this occurs on engraftment or soon thereafter. With regard to MF-related megakaryocytic anomalies (hyperchromasia, cloud-like nuclei, clustering) and increased M:E ratios, resolution was variable. These features were seldom estimated in the early post allo-HCT period but normalisation could be seen early following sustained engraftment. The resolution of bone marrow fibrosis was highly variable and, in some cases, takes over a year (6-23 months), as does resolution of microvasculature anomalies such as increased vessel density. Complete resolution of reticulin fibrosis has been reported in $>90 \%$ patients at twelve months following myeloablative (high intensity) conditioning (MAC) or RIC transplants. The dynamics of marrow fibrosis resolution with regard to clinical phenotype and outcomes have been reported previously $(25,26)$. Kroger et al evaluated the degree of resolution of fibrosis at day +30 and day +100 in 57 patients with PMF or Post Essential Thrombocythaemia (PET-) or Post Polycythaemia Vera (PPV-) MF (26). By day $+100,>50 \%$ of patients 
had either had no change in fibrosis grade or a 'one grade reduction' only. Those with ongoing grade 2-3 MF (as per European consensus / WHO grading) at day +100 had higher transfusion burdens. There was discordance between the rate of resolution of fibrosis and clearance of MRD despite correlation of fibrosis resolution with degree of donor chimerism. Early clearance (a 2 or 3 grade reduction) by day +100 is associated with improved graft function, a reduced incidence of relapse and good longterm outcome (Five-year OS based on fibrosis score at day +100 was $96 \%$ for MF0/1 vs. $57 \%$ for MF2/3). Complete resolution after one year occurred in the vast majority of successful allo-HCT. Of note, there appear to be variable responses with respect to modulation of new bone deposition (osteosclerosis) post allo-HC. As a result, its presence cannot be used, in our opinion, to either confirm CR or define relapse (25).

\section{Suggested Marrow Evaluation following MF allo-HCT}

In our opinion, it is essential to have a baseline bone marrow trephine sample to allow comparison with the post allo-HCT samples. Bone marrow aspirate evaluation is usually uninformative due to low cell yields. While decalcification protocols vary between institutions, EDTA decalcification yields optimal morphology. Trephine biopsy frequency is often centre- and patient- dependent, but we would suggest a day+100 and $a+12$ months trephine as a minimum. Additional biopsies at +24 and +36 months, if feasible, would be useful to understand the kinetics of marrow and fibrosis response, as well as aiding in the evaluation of late relapse. As a practical recommendation, when relapse is identified using clinical, haematological, cytogenetic / molecular or chimerism criteria, then a bone marrow evaluation should also be performed.

Reports should encompass the following: (1) assessment of cellularity, (2) the myeloid: erythroid (ME) ratio, (3) megakaryocyte morphology and (4) general comments on engraftment and regeneration. The evaluation of reticulin and collagen fibrosis should be performed using the Gomori technique and Masson's trichrome stain, respectively. Fibrosis grading should utilise the WHO fibrosis score or the 
European consensus scoring system $(18,27)$. New bone formation should be assessed (osteosclerosis scoring system, assessed on haematoxilin and eosin stains)(28). Evidence of dysplasia should be evaluated and blast proportion estimated via immunohistochemistry (IHC; minimum CD34/ CD117 and if possible, an extended panel of TdT, HLA-DR, CD56 and CD123). Monocytic components can be assessed via CD14 (preferable) or CD68. One suggested optimal IHC panel for assessment of MF trephines hence incorporates: erythroid markers (one or more of CD71 / e-cadherin / glycophorin A / alpha- $\mathrm{Hb}$ ), myeloid markers (myeloperoxidase (MPO) +/- CD15), megakaryocyte markers (CD61/CD42b), monocyte/macrophage markers (CD68/CD14) and blast / stem cell markers (CD34 \& CD117 at a minimum, optimal panel would also include TdT, HLA-DR, CD56, and CD123).

\section{Detection of driver mutations in MF}

Screening investigations for the so-called 'driver mutations' (JAK2, MPL, CALR) performed on peripheral blood DNA will detect a mutation in $80-90 \%$ of patients with MF (29). It is recommended that diagnostic testing for JAK2 V617F should use a test with a limit of detection of 1-3\%. Although there are at present no consensus criteria for diagnostic testing limit of detection for either CALR exon 9 and MPL exon 10 mutations, an assay sensitivity of at least 5\% is suggested (29). Low-level CALR or MPL mutations at diagnosis are thought to be uncommon. A small minority of all cases tests positive for more than one MPN driver gene, particularly when using sensitive detection assays. These are currently considered as being of no specific clinical significance and one clone usually predominates. All such diagnostic or follow-up testing, whether driver mutation testing, MRD analysis or next generation sequencing (NGS, discussed below) should ideally be performed in an ISO 15189 accredited laboratory.

\section{Use of Next Generation Sequencing Panels in MF at diagnosis or prior to allo-HCT}

The availability of NGS varies widely. Contrasting data exist regarding the impact of additional somatic mutations on relapse risk, although the number of patients harbouring such mutations has been 
limited in the majority of studies. For instance, a higher risk of relapse has been observed in ASXL1mutated cases of Primary MF (PMF) undergoing allo-HCT in some studies $(30,31)$ though not in others(32-34). The Fred Hutchinson group reported a higher risk of relapse in patients with $\geq 3$ mutations in addition to JAK2 or CALR, independent of DIPSS-plus risk (33). NGS panels can also be helpful in identifying a clonal marker in cases of 'triple negative' MF. We recommend that, at a minimum, MF allo-HCT candidates are screened using an NGS panel for the gene sets included in the mutation-enhanced international prognostic scoring systems for transplant-age patients -MIPPS70+ v2 scoring system -(which includes the genetically inspired prognostic scoring system (GIPSS)) namely; ASXL1, SRSF2, EZH2, IDH1, IDH2, U2AF1Q157 (and CALR status), although we recognise that wider genomic analysis provides additional prognostic value $(35,36)$. There is a paucity of clinical data to define the appropriate level of detection (LOD). The majority of laboratories use a LOD of $5 \%$ but this requires validation by each laboratory.

\section{MRD monitoring in MF allo-HCT- JAK2/CALR/MPL}

The detection of JAK2/CALR/MPL mutations pre-transplant facilitates the assessment of measurable residual disease (MRD) dynamics post-allo-HCT by allowing for the detection of 'molecular relapse'. Accumulating data support the prognostic relevance of MRD monitoring in MF allo-HCT. For example, in a cohort of $30 \mathrm{MF}$ allo-HCT patients, the detection of a JAK2 V617F allele burden $>1 \%$ on day +28 was associated with a higher risk of relapse and worse overall outcomes (37). Shah et al suggested that detection of a JAK2 V617 allele burden of $>0.05 \%$ by allele specific (AS) qPCR within the first 180 days post-transplant would be the optimal cut-off point to identify patients at risk of relapse (38). The largest study, reported from the Hamburg group, investigated the value of MRD analysis in 136 patients undergoing RIC allo-HCT. The rates of molecular clearance varied according to mutation type; Day +100 clearance was higher for CALR (92\%) than for JAK2 V617F (67\%) and MPL (75\%)(39). However, the sensitivity of the technique for the detection of CALR ranged from $0.02 \%$ to $1 \%$, lower than that for JAK2 or MPL (0.01\%). This may explain these different rates of molecular response as 
opposed to $C A L R+$ patients having better responses than other genotypes. Patients with detectable molecular disease at day +100 or at day +180 had a significantly higher risk of clinical relapse within five years compared to patients with undetectable disease ( $62 \%$ vs $10 \%, \mathrm{P}<0.001$ and $70 \%$ vs $10 \%$, $\mathrm{P}<0.001$, respectively), irrespective of the underlying mutation. These figures illustrate the prognostic value of residual minimal disease. Multivariate analysis revealed that detectable MRD at day+ 180 (HR $8.36,95 \% \mathrm{Cl}: 2.76-25.30, \mathrm{P}<0.001)$ was a significant risk factor for subsequent relapse, highlighting the importance of MRD monitoring. MRD can guide utilisation of adoptive immunotherapy with DLI. However, despite these studies, our survey of 'real world' practice revealed wide variations in practice with regard to monitoring with $25 \%$ of centres evaluating MRD status only when triggered by haematological or clinical findings suggesting relapse. Furthermore, additional work is required to standardise technical aspects of MRD tests.

The EBMT recommendations for chimerism and measurable residual disease (MRD) assessment following MF allo-HCT are shown in Table 2.

\section{Differential diagnoses in MF patients with cytopaenias}

Given the varying rates of resolution of fibrosis and splenomegaly in parallel with the individual dynamics of MRD clearance and achievement of full donor chimerism, defining relapse, particularly within the first six months following MF allo-HCT, is challenging. While the diagnosis of post-transplant relapse is relatively easy in patients with myeloproliferative features, it can be much more difficult in cytopenic patients. Indeed, a comprehensive laboratory work-up and other tests are required in order to rule out other causes in patients developing post-transplant cytopaenias. Figure 1 provides a suggested algorithm for the evaluation of post-transplant cytopaenias in MF patients.

It is of pivotal importance to be able to differentiate between GF, PGF and relapse in MF allo-HCT as both the prognostic implications and the management strategies differ. Most frequently, clinicians 
appear to use a combination of clinical findings: failure of resolution or re-emergence of splenomegaly; changes in blood counts/ blood smear; and molecular, cytogenetic and chimerism findings to decide if relapse has occurred following MF allo-HCT, leading to marked variation in relapse criteria and management approaches. There is no uniformly accepted scoring system that can accurately predict the risk of relapse. There is also the possibility of overlapping situations. In Table 3, we have summarised the characteristic findings seen in GF, PGF and relapse. Use of these criteria may improve the accuracy and uniformity of reporting across centres and to guide interventions such as DLI and referral for a second allo-HCT. More systematic use of these definitions will aid in the collection of more robust clinical data and contribute to their future refinement.

\section{Management Strategies}

\section{Graft failure}

Strategies to address risks of graft failure include treatments to reduce splenomegaly (JAK inhibitors), selection of a CMV-seronegative donor for a CMV-seronegative recipient, the evaluation of donor-specific antibodies in HLA haplo-identical or mismatched donor allo-HCT, and patient-stratified conditioning intensity and T cell depletion approaches. Recommendations on the management of GF in MF allo-HCT are shown in Table 4.

\section{Poor graft function}

As introduced above in the cohort reported from the Hamburg group, PGF patients were found to have similar outcomes at three years when compared to those who did not have PGF. However, this most likely reflects intervention with a CD34+ selected stem cell boost (14). Whether the pre-allo-HCT use of JAK inhibitors will affect the incidence of poor graft function in MF allo-HCT remains unknown. Klyuchnikov et al reported on outcomes following CD34+ selected stem cell boost without further conditioning in 32 patients with poor graft function, 14 of whom had MF, with a median interval of five (range, 2-228) months between allo-HCT and infusion of the CD34+ SCB (median CD34+ cell dose: 
$3.4 \times 10^{6} / \mathrm{kg}$ ). Haematological improvement was observed in $81 \%$ of patients, occurring at a median of 30 (range, 14-120) days. The cumulative incidence of grades II-IV acute GVHD was $17 \%$ and chronic GVHD 26\%(13). The use of a CD34+ stem cell boost in this setting has been reported by other groups $(12,16)$. There is insufficient evidence, in our view, to suggest the routine use of either thrombopoietin agonists or mesenchymal stem cell infusions in the management of poor graft function.

There is no consensus on management strategies to either reduce the risk or treat established poor graft function in MF allo-HCT. The degree of splenomegaly pre-allo-HCT, HLA-sensitisation, iron overload, conditioning platform choice/intensity and persistence of bulky splenomegaly following allo-HCT all contribute to the cumulative risk and hence treatment approach. There is a lack of randomised trial evidence to guide such approaches. The recommendations in Table $\mathbf{5}$ therefore represent an expert consensus view.

\section{Post-transplant relapse}

\section{Donor Lymphocyte Infusions (DLI)}

The first reports demonstrating evidence of a graft-versus-MF effect and highlighting the potential efficacy of DLI were published over two decades ago (40-42). The potential use of DLI should be considered in three discrete settings: prophylactic, pre-emptive and salvage.

\section{Prophylactic DLI}

There is no evidence to date to support the routine use of prophylactic DLI in MF allo-HCT. Controlled studies to investigate such an approach would be of interest in high risk and accelerated phase disease.

Pre-emptive DLI

At present, pre-emptive MRD-triggered approaches are the preferred setting for adoptive DLI use. Persistent MRD, increasing mixed patient chimerism and molecular relapse, as defined above, are the 
most frequent indications. The weaning and cessation of immunosuppression is generally required prior to pre-emptive DLI. Pre-emptive approaches have demonstrated higher efficacy compared to salvage approaches after frank haematological/ clinical relapse has occurred $(43,44)$. By way of example, Kroger et al reported on $17 \mathrm{MF}$ RIC allo-HCT cases who received DLI; in eight patients, the use of pre-emptive DLI was triggered by MRD detection of the JAK2 V617F mutation and nine cases were salvaged by DLI. The median time from allo-HCT was 269 (range, 127-1570) days. The median time to achieve complete remission was 79 (range, 31-495) days. The overall rate of complete molecular remission was $68 \%$, higher in the pre-emptive group than in the salvage group $(100 \%$ vs $44 \% ; p=.04)$. Our preference is for an escalating dose regimen, where feasible, as opposed to high dose 'bulk DLI', to reduce the risk of severe GVHD (44-46). The dosing regimen of choice is dependent on the transplant platform, the degree of T cell depletion and the donor source. Suggested approaches are shown in Table 6. The goal of DLI-based therapy should be clear and may include achievement of $C R$, ideally MRD negative if there is a suitable marker, or the achievement of full donor chimerism. The continued administration of escalating dose DLI using the end-point of clinically significant GVHD is no longer recommended. It is not currently possible to provide more specific recommendations regarding the timing of DLI or the duration of an escalating dose regimen-based approach given the lack of trial data. The decisions should be based on ongoing clinical assessment of the competing risks of relapse and GVHD. Donor chimerism and MRD, where applicable, should be evaluated after each course. Patients who achieve the targeted endpoints should continue to undergo serial monitoring.

\section{Salvage DLI}

Pre-emptive approaches take precedence over salvage DLI approaches. Lower rates of response are observed when compared to pre-emptive approaches $(43,44)$.

EBMT CMWP recommendations on DLI approaches in MF Allo-HCT are shown in Table 6. 


\section{Dosing of DLI}

The dose of DLI depends on the type of donor and the degree of HLA-matching. In addition, subsequent DLI can be given every six-to-eight weeks in the absence of GVHD grade $>1$ and if no significant response has been observed.

Recommendations on DLI approaches including dosing and scheduling based on donor type are shown in Table 7.

\section{Timing of DLI}

The practice survey introduced above revealed marked variation between allo-HCT centres with regard to DLI timing, with some using DLI as early as day +30 for persistent MRD and differing chimerism thresholds between institutions (4). As stated in the EBMT handbook, it is not possible to give precise advice on the timing and dosing schedules for DLI in MF allo-HCT and there is a focus on the collection of more such data in the cellular therapy registries (10). The detection of MRD or falling donor myeloid chimerism between day +100 and day +180 frequently prompts the weaning of immunosuppressive therapy with a view to escalating dose regimen $\mathrm{DLI}$, if required thereafter, in the absence of GVHD. Routine practice is to administer DLI every eight-to-twelve weeks until the end point is achieved. No further DLI is given following the development of GVHD. Improving uniformity in practice may aid in the development of evidence-based dosing schedules.

\section{Combination therapy with DLI}

There is no evidence to date to support the routine use of hypomethylating agents, JAK inhibitors, interferon-based therapies or intensive chemotherapy approaches in combination with DLI. Such approaches remain experimental and require further evaluation in a clinical trial setting. 


\section{Failure to respond to DLI with progressive disease}

If patients do not respond to either escalating dose regimen or salvage DLI and relapse has occurred, then patient suitability for a second allo-HCT should be considered. However, this is often reserved for fitter, younger individuals with a good performance status who are felt to have sufficient reserve to undergo such an approach. Otherwise, the choice between novel agents in clinical trials, the use of JAKi to address constitutional and splenic symptoms or palliative approaches will depend on patient status, clinical context and availability.

\section{JAK inhibitor use for emerging or established relapse}

To date, there is no evidence to support the use of JAKi post MF allo-HCT in emerging or frank relapse. The Hamburg group reported on $10 \mathrm{MF}$ allo-HCT cases who relapsed and had mixed chimerism (47). All received ruxolitinib at a median dose of $10 \mathrm{mg}$ twice a day (range, 5-20mg), but all progressed. Further evaluation is required in this setting, in particular in combination with $\mathrm{DLI}$. It is therefore our view that routine use cannot be recommended. There is, however, a possible role post-relapse for the control of splenomegaly, MF-related symptoms and potentially as 'a bridge' to a second allo-HCT in suitable individuals.

\section{Role of second allo-HCT for Relapse or Graft Failure}

Data in the literature concerning the role of a second allo-HCT for MF remains sparse, although there have been some comprehensive recent publications $(43,48,49)$. Most patients are not suitable so patient selection is paramount. An adequate Karnofsky performance Score (KPS) in the absence of significant co-morbidities appears to be essential. The main indication is relapsed disease with no response to DLI (or lack of available DLI) or primary/ secondary graft failure. Furthermore, in the context of persistent poor graft function, as discussed above, options include a selected CD34+ stem cell boost or escalation to a conditioned second allo-HCT. Bridging strategies are patient-specific, ranging from proceeding straight to allo-HCT, the use of cytoreductive therapies or JAK inhibitors. The 
CMWP recently reported on $216 \mathrm{MF}$ patients undergoing second allo-HCT. The vast majority were RIC allo-HCT, for either relapsed disease $(56 \%)$ or graft failure (31\%), at a median interval from the first procedure of eight months(48). The reported three-year OS estimate was $42 \%$ (95\% confidence interval [CI]: 34-49), with a median OS of 23 months (95\% Cl: 10.9-35.7), and 3-year RFS estimate was 39\% (95\% Cl: 31-48). For both OS and RFS, univariate analysis revealed improved outcomes when transplant occurred after the first twelve months, when the indication was relapse rather than graft failure (due to increased NRM) and when the recipient had a KPS $>90$. There was no benefit in choosing an alternative donor over the original donor unless there was a contraindication or there were donordirected antibodies. Reports on the use of haploidentical donors in second MF allo-HCT are very limited. The optimal conditioning regimen for a second transplant remains unclear; however, it should ideally be of low toxicity and exert a strong 'anti-MF' effect. The Hamburg group reported a single centre experience $(n=33)$ of second allo-HCT for MF using treosulphan (36-42g/m2)-based conditioning in combination with fludarabine and ATG (49). Timely engraftment occurred in all but one patient and the rates of full donor chimerism were satisfactory. The TRM was $16 \%$ at day +100 , and the five-year disease-free survival and OS were $45 \%$ and $47 \%$, respectively. Recommendations regarding a second allo-HCT in MF are shown in Table 8. 


\section{Conclusions}

We acknowledge that these proposed new working definitions of relapse remain unvalidated and will not cover all possible clinical scenarios. They undoubtedly oversimplify the dynamic interplay between blood counts, marrow morphology, the disease clone, and donor-recipient chimerism following an allo-HCT. There is, in addition, the highly variable rate of modulation of marrow topography and fibrosis resolution over time. However, there is an evident need within the field to develop practical empiric definitions of the different kinds of relapse post MF allo-HCT and our suggested guidelines may provide the basis for more consistent reporting in clinical studies and, hence, more informed decisions in routine clinical practice. 


\section{References}

1. McLornan DP, Yakoub-Agha I, Robin M, Chalandon Y, Harrison CN, Kroger N. State-of-the-art review: allogeneic stem cell transplantation for myelofibrosis in 2019. Haematologica. 2019;

2. Kröger NM, Deeg JH, Olavarria E, Niederwieser D, Bacigalupo A, Barbui T, et al. Indication and management of allogeneic stem cell transplantation in primary myelofibrosis: a consensus process by an EBMT/ELN international working group. Leukemia. 2015 Nov;29(11):2126-33.

3. McLornan DP, Szydlo R, Robin M, van Biezen A, Koster L, Blok HJP, et al. Outcome of patients with Myelofibrosis relapsing after allogeneic stem cell transplant: a retrospective study by the Chronic Malignancies Working Party of EBMT. Br J Haematol. 2018;182(3):418-22.

4. McLornan DP, Sirait T, Hernández-Boluda JC, Czerw T, Hayden P, Yakoub-Agha I. European wide survey on allogeneic haematopoietic cell transplantation practice for myelofibrosis on behalf of the EBMT chronic malignancies working party. Curr Res Transl Med. 2020 Oct 15;103267.

5. McLornan D, Szydlo R, Koster L, Chalandon Y, Robin M, Wolschke C, et al. Myeloablative and Reduced-Intensity Conditioned Allogeneic Hematopoietic Stem Cell Transplantation in Myelofibrosis: A Retrospective Study by the Chronic Malignancies Working Party of the European Society for Blood and Marrow Transplantation. Biol Blood Marrow Transplant. 2019;25(11):2167-71.

6. Wolff S. Second hematopoietic stem cell transplantation for the treatment of graft failure, graft rejection or relapse after allogeneic transplantation. Bone Marrow Transplant. 2002 Apr;29(7):545-52.

7. Valcárcel D, Sureda A. Graft Failure. In: Carreras E, Dufour C, Mohty M, Kröger N, editors. The EBMT Handbook [Internet]. Cham: Springer International Publishing; 2019 [cited 2021 Feb 13]. p. 30713. Available from: http://link.springer.com/10.1007/978-3-030-02278-5_41 
8. Olsson R, Remberger M, Schaffer M, Berggren DM, Svahn B-M, Mattsson J, et al. Graft failure in the modern era of allogeneic hematopoietic SCT. Bone Marrow Transplant. 2013 Apr;48(4):537-43.

9. Hernández-Boluda JC, Pereira A, Kröger N, Beelen D, Robin M, Bornhäuser M, et al. Determinants of survival in myelofibrosis patients undergoing allogeneic hematopoietic cell transplantation. Leukemia. 2021 Jan;35(1):215-24.

10. Carreras E, Dufour C, Mohty M, Kröger N, editors. The EBMT Handbook: Hematopoietic Stem Cell Transplantation and Cellular Therapies [Internet]. Cham: Springer International Publishing; 2019 [cited 2021 Feb 10]. Available from: http://link.springer.com/10.1007/978-3-030-02278-5

11. Keyzner A, Han S, Shapiro S, Moshier E, Schorr E, Petersen B, et al. Outcome of Allogeneic Hematopoietic Stem Cell Transplantation for Patients with Chronic and Advanced Phase Myelofibrosis. Biology of Blood and Marrow Transplantation. 2016 Dec;22(12):2180-6.

12. Stasia A, Ghiso A, Galaverna F, Raiola AM, Gualandi F, Luchetti S, et al. CD34 Selected Cells for the Treatment of Poor Graft Function after Allogeneic Stem Cell Transplantation. Biology of Blood and Marrow Transplantation. 2014 Sep;20(9):1440-3.

13. Klyuchnikov E, El-Cheikh J, Sputtek A, Lioznov M, Calmels B, Furst S, et al. CD34+-Selected Stem Cell Boost without Further Conditioning for Poor Graft Function after Allogeneic Stem Cell Transplantation in Patients with Hematological Malignancies. Biology of Blood and Marrow Transplantation. 2014 Mar;20(3):382-6.

14. Alchalby H, Yunus D-R, Zabelina T, Ayuk F, Kröger N. Incidence and risk factors of poor graft function after allogeneic stem cell transplantation for myelofibrosis. Bone Marrow Transplant. 2016 Sep;51(9):1223-7. 
15. Zhao Y, Gao F, Shi J, Luo Y, Tan Y, Lai X, et al. Incidence, Risk Factors, and Outcomes of Primary Poor Graft Function after Allogeneic Hematopoietic Stem Cell Transplantation. Biology of Blood and Marrow Transplantation. 2019 Sep;25(9):1898-907.

16. M. Cuadrado M, Richard M. Szydlo, Mike Watts, Nishil Patel, Hanna Renshaw, Jude Dorman, et al. Predictors of recovery following allogeneic CD34+-selected cell infusion without conditioning to correct poor graft function. haematol. 2019 Nov 21;105(11):2639-46.

17. Tefferi A, Cervantes F, Mesa R, Passamonti F, Verstovsek S, Vannucchi AM, et al. Revised response criteria for myelofibrosis: International Working Group-Myeloproliferative Neoplasms Research and Treatment (IWG-MRT) and European LeukemiaNet (ELN) consensus report. Blood. 2013 Aug 22;122(8):1395-8.

18. Thiele J, Kvasnicka HM, Facchetti F, Franco V, van der Walt J, Orazi A. European consensus on grading bone marrow fibrosis and assessment of cellularity. Haematologica. 2005 Aug;90(8):1128-32.

19. Tefferi A, Nicolosi M, Mudireddy M, Lasho TL, Gangat N, Begna KH, et al. Revised cytogenetic risk stratification in primary myelofibrosis: analysis based on 1002 informative patients. Leukemia. 2018 May;32(5):1189-99.

20. Jain T, Kunze KL, Mountjoy L, Partain DK, Kosiorek H, Khera N, et al. Early post-transplantation factors predict survival outcomes in patients undergoing allogeneic hematopoietic cell transplantation for myelofibrosis. Blood Cancer J. 2020 Mar;10(3):36.

21. Srour SA, Olson A, Ciurea SO, Desai P, Bashir Q, Oran B, et al. Mixed myeloid chimerism and relapse of myelofibrosis after allogeneic stem cell transplantation. Haematologica. $2019 \mathrm{Jul}$ 11; haematol.2019.223503. 
22. Deeg HJ, Salit RB, Monahan T, Schoch G, McFarland C, Scott BL, et al. Early Mixed Lymphoid Donor/Host Chimerism is Associated with Improved Transplant Outcome in Patients with Primary or Secondary Myelofibrosis. Biology of Blood and Marrow Transplantation. 2020 Dec;26(12):2197-203.

23. Sale GE, Deeg HJ, Porter BA. Regression of Myelofibrosis and Osteosclerosis following Hematopoietic Cell Transplantation Assessed by Magnetic Resonance Imaging and Histologic Grading. Biology of Blood and Marrow Transplantation. 2006 Dec;12(12):1285-94.

24. Tamari R, Mughal TI, Rondelli D, Hasserjian R, Gupta V, Odenike O, et al. Allo-SCT for myelofibrosis: reversing the chronic phase in the JAK inhibitor era? Bone Marrow Transplant. 2015 May;50(5):628-36.

25. Thiele J, Kvasnicka HM, Dietrich H, Stein G, Hann M, Kaminski A, et al. Dynamics of bone marrow changes in patients with chronic idiopathic myelofibrosis following allogeneic stem cell transplantation. Histol Histopathol. 2005 Jul;20(3):879-89.

26. Kröger N, Zabelina T, Alchalby H, Stübig T, Wolschke C, Ayuk F, et al. Dynamic of Bone Marrow Fibrosis Regression Predicts Survival after Allogeneic Stem Cell Transplantation for Myelofibrosis. Biology of Blood and Marrow Transplantation. 2014 Jun;20(6):812-5.

27. Arber DA, Orazi A, Hasserjian R, Borowitz MJ, Beau MM, Bloomfield CD, et al. The 2016 revision to the World Health Organization classification of myeloid neoplasms and acute leukemia. Blood. 2016;127(20):2391-406.

28. Kvasnicka HM, Beham-Schmid C, Bob R, Dirnhofer S, Hussein K, Kreipe H, et al. Problems and pitfalls in grading of bone marrow fibrosis, collagen deposition and osteosclerosis - a consensusbased study. Histopathology. 2016 May;68(6):905-15. 
29. Bench AJ, White HE, Foroni L, Godfrey AL, Gerrard G, Akiki S, et al. Molecular diagnosis of the myeloproliferative neoplasms: UK guidelines for the detection of JAK2 V617F and other relevant mutations. Br J Haematol. 2013 Jan;160(1):25-34.

30. Gagelmann N, Ditschkowski M, Bogdanov R, Bredin S, Robin M, Cassinat B, et al. Comprehensive clinical-molecular transplant scoring system for myelofibrosis undergoing stem cell transplantation. Blood. 2019 May 16;133(20):2233-42.

31. Kröger N, Panagiota V, Badbaran A, Zabelina T, Triviai I, Araujo Cruz MM, et al. Impact of Molecular Genetics on Outcome in Myelofibrosis Patients after Allogeneic Stem Cell Transplantation. Biology of Blood and Marrow Transplantation. 2017 Jul;23(7):1095-101.

32. Ali H, Aldoss I, Yang D, Mokhtari S, Khaled S, Aribi A, et al. MIPSS70+ v2.0 predicts long-term survival in myelofibrosis after allogeneic HCT with the Flu/Mel conditioning regimen. Blood Advances. 2019 Jan 8;3(1):83-95.

33. Tamari R, Rapaport F, Zhang N, McNamara C, Kuykendall A, Sallman DA, et al. Impact of HighMolecular-Risk Mutations on Transplantation Outcomes in Patients with Myelofibrosis. Biology of Blood and Marrow Transplantation. 2019 Jun;25(6):1142-51.

34. Stevens EA, Jenkins IC, Beppu LW, Zhang Q, Salit R, Loeb KR, et al. Targeted Sequencing Improves DIPSS-Plus Prognostic Scoring in Myelofibrosis Patients Undergoing Allogeneic Transplantation. Biology of Blood and Marrow Transplantation. 2020 Jul;26(7):1371-4.

35. Grinfeld J, Nangalia J, Baxter EJ, Wedge DC, Angelopoulos N, Cantrill R, et al. Classification and Personalized Prognosis in Myeloproliferative Neoplasms. N Engl J Med. 2018 Oct 11;379(15):1416-30. 
36. Luque Paz D, Riou J, Verger E, Cassinat B, Chauveau A, lanotto J-C, et al. Genomic analysis of primary and secondary myelofibrosis redefines the prognostic impact of ASXL1 mutations: a FIM study. Blood Advances. 2021 Mar 9;5(5):1442-51.

37. Lange T, Edelmann A, Siebolts U, Krahl R, Nehring C, Jäkel N, et al. JAK2 p.V617F allele burden in myeloproliferative neoplasms one month after allogeneic stem cell transplantation significantly predicts outcome and risk of relapse. Haematologica. 2013 May;98(5):722-8.

38. Shah MV, Patel KP, Luthra R, Shamanna RK, Mehrotra M, Champlin RE, et al. Real Time PCR Detects Relapse of JAK2 V617F Myelofibrosis Earlier Than Pyrosequencing after Allogeneic Transplantation. Biology of Blood and Marrow Transplantation. 2017 Mar;23(3):S298-9.

39. Wolschke C, Badbaran A, Zabelina T, Christopeit M, Ayuk F, Triviai I, et al. Impact of molecular residual disease post allografting in myelofibrosis patients. Bone Marrow Transplant. 2017 Nov;52(11):1526-9.

40. Guardiola P, Anderson JE, Bandini G, Cervantes F, Runde V, Arcese W, et al. Allogeneic stem cell transplantation for agnogenic myeloid metaplasia: a European Group for Blood and Marrow Transplantation, Société Française de Greffe de Moelle, Gruppo Italiano per il Trapianto del Midollo Osseo, and Fred Hutchinson Cancer Research Center Collaborative Study. Blood. 1999 May 1;93(9):2831-8.

41. Byrne JL, Beshti H, Clark D, Ellis I, Haynes AP, Das-Gupta E, et al. Induction of remission after donor leucocyte infusion for the treatment of relapsed chronic idiopathic myelofibrosis following allogeneic transplantation: evidence for a 'graft vs. myelofibrosis' effect. $\mathrm{Br} \mathrm{J}$ Haematol. 2000 Feb;108(2):430-3.

42. Cervantes F, Rovira M, Urbano-Ispizua A, Rozman M, Carreras E, Montserrat E. Complete remission of idiopathic myelofibrosis following donor lymphocyte infusion after failure of 
allogeneic transplantation: demonstration of a graft-versus-myelofibrosis effect. Bone Marrow Transplant. 2000 Sep;26(6):697-9.

43. Klyuchnikov E, Holler E, Bornhäuser M, Kobbe G, Nagler A, Shimoni A, et al. Donor lymphocyte infusions and second transplantation as salvage treatment for relapsed myelofibrosis after reduced-intensity allografting. Br J Haematol. 2012 Oct;159(2):172-81.

44. Kröger N, Alchalby H, Klyuchnikov E, Badbaran A, Hildebrandt $\mathrm{Y}$, Ayuk F, et al. JAK2-V617Ftriggered preemptive and salvage adoptive immunotherapy with donor-lymphocyte infusion in patients with myelofibrosis after allogeneic stem cell transplantation. Blood. 2009 Feb 19;113(8):1866-8.

45. Peggs KS, Thomson K, Hart DP, Geary J, Morris EC, Yong K, et al. Dose-escalated donor lymphocyte infusions following reduced intensity transplantation: toxicity, chimerism, and disease responses. Blood. 2004 Feb 15;103(4):1548-56.

46. Dholaria B, Savani BN, Labopin M, Luznik L, Ruggeri A, Mielke S, et al. Clinical applications of donor lymphocyte infusion from an HLA-haploidentical donor: consensus recommendations from the Acute Leukemia Working Party of the EBMT. Haematologica. 2020 Jan;105(1):47-58.

47. Janson D, Ayuk FA, Wolschke C, Christopeit M, Badbaran A, von Pein U-M, et al. Ruxolitinib for Myelofibrosis Patients Relapsing after Allogeneic Hematopoietic Transplantation. Blood. 2016 Dec 2;128(22):1948-1948.

48. Nabergoj M, Wang J, Robin M, Kröger N, Angelucci E, Poire X, et al. Outcomes Following Second Allogenic Haematopoietic Cell Transplantation in Patients with Myelofibrosis: A Retrospective Study on Behalf of the Chronic Malignancies Working Party of EBMT. Blood. 2019 Nov 13;134(Supplement_1):698-698. 
49. Atagunduz IK, Klyuchnikov E, Wolschke C, Janson D, Heidenreich S, Christopeit M, et al. Treosulfan-Based Conditioning Regimen for Second Allograft in Patients with Myelofibrosis. Cancers. 2020 Oct 23;12(11):3098.

50. Atagunduz IK, Christopeit M, Ayuk F, Zeck G, Wolschke C, Kröger N. Incidence and Outcome of Late Relapse after Allogeneic Stem Cell Transplantation for Myelofibrosis. Biology of Blood and Marrow Transplantation. 2020 Dec;26(12):2279-84.

51. Polverelli N, Mauff K, Kröger N, Robin M, Beelen D, Beauvais D, et al. Impact of spleen size and splenectomy on outcomes of allogeneic hematopoietic cell transplantation for myelofibrosis: A retrospective analysis by the chronic malignancies working party on behalf of European society for blood and marrow transplantation (EBMT). Am J Hematol. 2021 Jan;96(1):69-79.

52. Petrovic A, Hale G. Clinical options after failure of allogeneic hematopoietic stem cell transplantation in patients with hematologic malignancies. Expert Review of Clinical Immunology. 2011 Jul;7(4):515-27.

53. Robin M, Espérou H, De Latour RP, Petropoulou AD, Xhaard A, Ribaud P, et al. correspondence: Splenectomy after allogeneic haematopoietic stem cell transplantation in patients with primary myelofibrosis: Correspondence. British Journal of Haematology. 2010 Sep;150(6):721-4.

54. for the Nordic MPD Study Group, Abelsson J, Merup M, Birgegård G, WeisBjerrum O, Brinch L, et al. The outcome of allo-HSCT for 92 patients with myelofibrosis in the Nordic countries. Bone Marrow Transplant. 2012 Mar;47(3):380-6.

55. De Vos J, Baudoux E, Bay J-O, Calmels B, Cras A, El Cheikh J, et al. Injections de lymphocytes du donneur (DLI) : recommandations de la Société francophone de greffe de moelle et de thérapie cellulaire (SFGM-TC). Bulletin du Cancer. 2019 Jan;106(1):S35-9. 


\section{Figure Legends}

Figure 1: Differential diagnosis in MF patients with post-transplant cytopaenias 


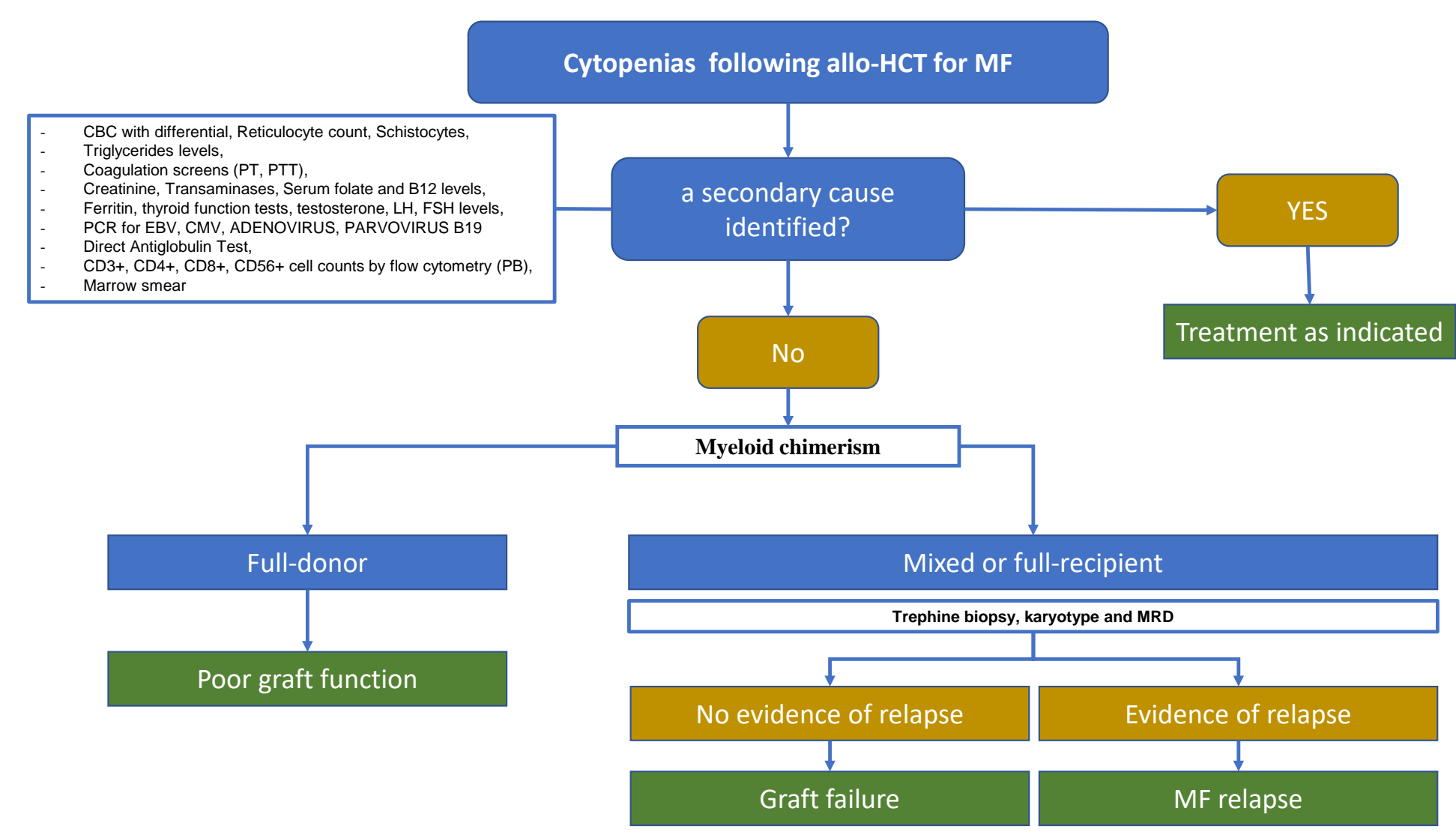




\begin{tabular}{|c|c|c|}
\hline & Required criteria (duration $>12$ weeks) & Notes \\
\hline Complete remission & $\begin{array}{l}\text { Bone marrow: Age-adjusted normocellularity; } \\
<5 \% \text { blasts; } \leq \text { grade } 1 \mathrm{MF}^{*} \\
\text { and } \\
\text { Peripheral blood: } \\
\text { Haemoglobin } \geq 100 \mathrm{~g} / \mathrm{L} \text { and }<\mathrm{UNL} \text {; } \\
\text { neutrophil count } \geq 1.0 \times 10^{9} / \mathrm{L} \text { and }<\mathrm{UNL} ; \\
\text { Platelet count } \geq 100 \times 10^{9} / \mathrm{L} \text { and }<\mathrm{UNL} ; \\
<2 \% \text { immature myeloid cells** } \\
\text { and } \\
\text { Clinical: Resolution of disease-related symptoms; } \\
\text { spleen and liver not palpable; no evidence of } \\
\text { extramedullary haematopoiesis }\end{array}$ & $\begin{array}{l}* \text { Grading of MF according to } \\
\text { the European classification } \\
\text { (WHO Fibrosis score)(18) } \\
* *<5 \% \text { immature myeloid } \\
\text { cells in splenectomised } \\
\text { patients. Immature myeloid } \\
\text { cells constitute blasts + } \\
\text { promyelocytes + myelocytes + } \\
\text { metamyelocytes + nucleated } \\
\text { red blood cells }\end{array}$ \\
\hline Cytogenetic Remission & $\begin{array}{c}\text { CR: eradication of a pre-existing abnormality } \\
\text { (N.B. the limit of detection may differ substantially } \\
\text { for different methods) }\end{array}$ & \\
\hline Molecular Remission & CR: Pre-existing abnormality no longer detectable & $\begin{array}{l}\text { Molecular response } \\
\text { evaluation must be analysed } \\
\text { in PB granulocytes and } \\
\text { requires confirmation by } \\
\text { repeat testing within six } \\
\text { months }\end{array}$ \\
\hline $\begin{array}{c}\text { Cytogenetic/ Molecular } \\
\text { Relapse }\end{array}$ & $\begin{array}{c}\text { Re-emergence of a pre-existing cytogenetic or } \\
\text { molecular abnormality that is confirmed on repeat } \\
\text { testing }\end{array}$ & \\
\hline
\end{tabular}

Table 1: Definition of complete remission of MF in the non-transplant setting, Adapted from the IWGMPN criteria (2013)(17). CR=Complete remission; $P B=$ peripheral blood 


\begin{tabular}{|c|c|c|}
\hline & Chimerism & MRD \\
\hline $\begin{array}{l}\text { Assessment } \\
\text { recommende } \\
\text { d time points }\end{array}$ & \multicolumn{2}{|c|}{$\begin{array}{c}\text { Day }+30 \text {, Day }+100 \text {, Day }+180 \text {, Day }+270 \text { and Day }+360 \text {, or as clinically required } \\
\text { As late relapses can occur, there is some evidence to suggest that } \\
\text { longer term chimerism testing may be useful(50) }\end{array}$} \\
\hline $\begin{array}{c}\text { Technique } \\
\text { and } \\
\text { interpretation }\end{array}$ & $\begin{array}{l}\text { Chimerism assessment is generally } \\
\text { performed on PB but bone marrow-based } \\
\text { analysis, if performed, should also be } \\
\text { assessed. PB lineage-specific chimerism is } \\
\text { recommended } \\
\text { Complete chimerism-when all } \\
\text { hematopoietic cells are of donor origin, } \\
\text { dependent on technique, but frequently } \\
\text { defined as }>95 \% \text { of cells analysed as being of } \\
\text { donor origin } \\
\text { Increasing mixed myeloid chimerism ( }>5 \% \text { in } \\
\text { the tested lineage when compared to the } \\
\text { previous sample of same type) is associated } \\
\text { with a higher risk of relapse }\end{array}$ & $\begin{array}{c}\text { Sensitive laboratory techniques are required } \\
\text { for MRD assessment, ideally with a sensitivity } \\
\text { of } 0.01-1 \% \text {. For JAK2 V617F monitoring, } \\
\text { laboratories should ideally use a quantitative } \\
\text { PCR, digital PCR or other sensitive } \\
\text { methodologies } \\
\text { Test accuracy may be validated by use of the } \\
\text { WHO Reference Panel } \\
\text { (NIBSC (www.nibsc.org) panel code 16/120) } \\
\text { Both CALR and MPL MRD monitoring have } \\
\text { been used for assessment of MRD } \\
\text { There is still a lack of standardisation of } \\
\text { quantitative results for CALR and MPL, hence } \\
\text { quantitative results should be interpreted } \\
\text { with caution and considered within the } \\
\text { clinical context }\end{array}$ \\
\hline Special cases & $\begin{array}{l}\text { Role of } \mathrm{CD} 34+\text { specific chimerism in } \mathrm{MF} \\
\text { requires further evaluation }\end{array}$ & $\begin{array}{l}\text { The use of extended NGS panels in MRD } \\
\text { monitoring is currently unstandardised and } \\
\text { hence remains a research tool. Clinical utility } \\
\text { should be evaluated is required in the context } \\
\text { of a clinical trial }\end{array}$ \\
\hline $\begin{array}{l}\text { Role in the } \\
\text { diagnosis of } \\
\text { relapse }\end{array}$ & $\begin{array}{r}\text { Chimerism assessment is often paired with } M \\
\text { and this is recommended tc } \\
\text { Utilising chimerism to predict and defi } \\
\text { interpretation of }\end{array}$ & $\begin{array}{l}\text { D assessment when there is a suitable marker } \\
\text { increase the predictive value } \\
\text { e relapse requires careful individualised } \\
\text { chimerism kinetics }\end{array}$ \\
\hline Other roles & $\begin{array}{l}\text { Chimerism assessment can guide } \\
\text { assessment of response to DLI or other } \\
\text { relapse-directed therapies } \\
\text { Accurate determination of chimerism is } \\
\text { technically challenging and testing } \\
\text { laboratories should participate in regular } \\
\text { external quality assurance schemes e.g., see } \\
\text { www.ukneqasli.co.uk }\end{array}$ & \\
\hline
\end{tabular}

Table 2: EBMT suggested recommendations for chimerism and minimal residual disease (MRD) assessment following MF allo-HCT 


\begin{tabular}{|c|c|c|c|c|c|}
\hline Predisposing factors & & Primary Graft Failure & Secondary Graft Failure & Poor Graft Function & Disease Relapse \\
\hline \multirow[t]{2}{*}{ Disease-related } & $\begin{array}{l}\text { Clinical } \\
\text { Factors }\end{array}$ & $\begin{array}{c}\text { Older Age? } \\
\text { Bulky splenomegaly } \\
\text { Iron Overload? } \\
\text { HLA-sensitisation } \\
\text { DSA in haploidentical allo-HCT }\end{array}$ & $\begin{array}{c}\text { Older Age? } \\
\text { Bulky splenomegaly } \\
\text { Iron Overload? } \\
\text { HLA-sensitisation } \\
\text { DSA in haploidentical allo-HCT }\end{array}$ & $\begin{array}{c}\text { Older age? } \mathrm{M}>\mathrm{F} \\
\text { Bulky splenomegaly } \\
\text { Prior HLA-sensitisation } \\
\text { DSA in haploidentical allo-HCT }\end{array}$ & Splenectomy status(51) \\
\hline & $\begin{array}{l}\text { Mutational } \\
\text { Profile effect }\end{array}$ & Lack of evidence & Lack of evidence & Lack of evidence & $\begin{array}{c}\text { Controversial, higher risk has been } \\
\text { suggested with } A S X L 1\end{array}$ \\
\hline \multirow[t]{2}{*}{ Transplant-related } & Donor & $\begin{array}{c}\text { Mismatched/ Haploidentical higher } \\
\text { rates } \\
\text { Low yield of CD34+ Cells }\end{array}$ & $\begin{array}{c}\text { Mismatched/ Haploidentical } \\
\text { higher rates } \\
\text { Low yield of CD34+ Cells }\end{array}$ & $\begin{array}{l}\text { Unrelated donors } \\
\text { Major ABO incompatibility } \\
\text { Low yield of CD34+ Cells }\end{array}$ & $\begin{array}{l}\text { Controversial, ? mismatched } \\
\text { unrelated donors/ haplo-identical }\end{array}$ \\
\hline & Conditioning & Effect of Intensity undetermined & Effect of Intensity undetermined & Effect of Intensity undetermined & Trends for RIC $>\mathrm{MAC}$ \\
\hline Timing post allo-HCT & & $\begin{array}{l}\text { Defined by day+28 (not cord where } \\
\text { it is day+42) }\end{array}$ & $\begin{array}{l}\text { Occurs after demonstration of } \\
\text { initial engraftment }\end{array}$ & $\begin{array}{l}\text { Lasting for }>2 \text { consecutive weeks } \\
\text { following documented engraftment, } \\
\text { beyond day+14 }\end{array}$ & $\begin{array}{l}\text { Most frequent within first 12- } \\
\text { months after allo-HCT but late } \\
\text { relapses can occur. }\end{array}$ \\
\hline \multicolumn{6}{|l|}{ Evaluation } \\
\hline Peripheral blood criteria & & $\begin{array}{c}<0.5 \times 10^{9} / \mathrm{L} \text { by day }+28, \\
\text { haemoglobin }<80 \mathrm{~g} / \mathrm{L} \text {, platelet } \\
\text { count }<20 \times 10^{9} / \mathrm{L}\end{array}$ & $\begin{array}{c}\text { ANC }<0.5 \times 10^{9} / \mathrm{L} \text { occurring after } \\
\text { initial engraftment }\end{array}$ & $\begin{array}{c}\text { Neutrophils } \leqslant 1.5 \times 10^{9} / \mathrm{L} \text {, platelet } \\
\text { count } \leqslant 30 \times 10^{9} / \mathrm{L}, \mathrm{Hb} \leqslant 85 \mathrm{~g} / \mathrm{L}\end{array}$ & $\begin{array}{l}\text { No set criteria. Evaluate for } \\
\text { persistent or emerging cytopaenia, } \\
\text { or proliferative features. }\end{array}$ \\
\hline Marrow smear & & $\begin{array}{l}\text { Frequently aparticulate and } \\
\text { hypocellular }\end{array}$ & $\begin{array}{l}\text { Frequently aparticulate and } \\
\text { hypocellular }\end{array}$ & $\begin{array}{l}\text { Frequently aparticulate and } \\
\text { hypocellular }\end{array}$ & $\begin{array}{c}\text { Frequently aparticulate and } \\
\text { hypocellular. Assess for features } \\
\text { suggestive of MF such as } \\
\text { megakaryocyte abnormalities }\end{array}$ \\
\hline Trephine biopsy & & $\begin{array}{c}\text { Frequently hypocellular and fibrosis } \\
\text { persists }\end{array}$ & $\begin{array}{l}\text { Frequently hypocellular and } \\
\text { fibrosis may persist }\end{array}$ & $\begin{array}{l}\text { Frequently hypocellular but may be } \\
\text { normo- or even hypercellular. }\end{array}$ & $\begin{array}{c}\text { See Morphological Relapse } \\
\text { definition }\end{array}$ \\
\hline Karyotype & & Not required for definition & Not required for definition & Not required for definition & $\begin{array}{c}\text { Detection of previously detected } \\
\text { chromosomal abnormality not } \\
\text { meeting the criteria for } \\
\text { morphological relapse }\end{array}$ \\
\hline MRD & & Not required for definition & Not required for definition & Not required for definition & $\begin{array}{l}\text { Reappearance of established MRD } \\
\text { marker after documented } \\
\text { clearance confirmed by } 2 \text { PB } \\
\text { samples collected } 28 \text { days apart }\end{array}$ \\
\hline Chimerism Analysis & & Predominant recipient chimerism & $\begin{array}{c}\text { Predominant recipient chimerism } \\
\text { In RIC setting, EBMT criteria } \\
\text { suggest }<5 \% \text { donor chimerism } \\
\text { but controversial }\end{array}$ & Full donor chimerism & $\begin{array}{l}\text { Sensitive techniques will detect } \\
\text { early increases in host chimerism } \\
\text { suggestive of emerging or } \\
\text { established relapse. }\end{array}$ \\
\hline
\end{tabular}

Table 3: Characteristics of primary and secondary GF, PGF and disease relapse in MF 
Prevention by minimising risk factors where possible and early detection is paramount

A bone marrow aspirate and trephine biopsy should be performed as soon as graft failure is expected

Cytogenetic analysis / Fluorescence in situ hybridisation (FISH; particularly if sex-mismatched allo-HCT) should be performed where appropriate

Both peripheral blood and marrow aspirate sample (where available) should be sent for chimerism analysis following local policies. Depending on practice, this could be whole blood or lineage-specific chimerism and whole marrow or CD34-selected chimerism

Consider myelosuppressive drugs, treatment of viral infections (particularly CMV), and treatment of GVHD

If suspected GF, changes in immunosuppressive therapy are dependent on timing post allo-HCT and the results of the above investigations

Growth factors are often administered though there is little supporting evidence. Frequently they do not improve counts in primary GF and are not a long term-solution

Donor Lymphocyte Infusions (DLI) may have a role in the context of falling donor chimerism and can convert some patients to full donor chimerism and remedy secondary GF; however, this is case-dependent and there are no reports specific to $M F(52)$

Recipients with primary GF with no functional haematopoiesis and pancytopaenia should be considered for a second allo-HCT using either the same or an alternative stem cell donor

In secondary GF, assess for and treat contributing factors such as CMV reactivation, uncontrolled GVHD and myelosuppressive drugs, as indicated. Individuals with true secondary GF should be considered for a second allo-HCT if feasible

Table 4: Recommendations for the investigation and management of Graft Failure in MF allo-HCT 
Infection prophylaxis based on time post allo-HCT, neutrophil count and lymphocyte subset recovery should be based on local institutional policies

Growth factor support with recombinant human EPO (RHuEPO) and GCSF can be considered based on local policies although this is not a long term solution.(14) There is insufficient evidence at present to support the routine use of thrombopoietin (TPO) agonists such as Eltrombopag. Their use remains experimental and more robust evidence is required

Consider a CD34+ selected stem cell boost (SCB), either fresh or cryopreserved, in the presence of full donor chimerism. This can successfully treat poor graft function and does not require further conditioning. The optimal timing of this approach, however, requires further evaluation, as does the associated risk of inducing $\operatorname{GVHD}(13,14,16)$

For some patients with persistent, bulky splenomegaly, there are reports of successful resolution following post allo-HCT splenectomy $(14,53)$

For eligible patients, in the presence of significant, severe and unresponsive poor graft function, consider a second allo-HCT

Insufficient evidence at present for the routine use of Mesenchymal Stem Cell infusions. Use remains experimental and more robust evidence is required

Table 5: Management of Poor Graft Function in MF allo-HCT 


\begin{tabular}{|c|c|c|c|}
\hline Modality of DLI & Indication for use & Comments & Supporting Evidence \\
\hline Prophylactic & Not established & $\begin{array}{l}\text { No evidence to support use in } \\
\text { higher risk or accelerated } \\
\text { phase disease to date }\end{array}$ & $\begin{array}{l}\text { Lack of supportive } \\
\text { evidence } \\
\text { Not recommended in } \\
\text { EBMT/ELN 2015 } \\
\text { consensus(2) } \\
\text { Requires evaluation in a } \\
\text { clinical trial setting }\end{array}$ \\
\hline \multirow[t]{2}{*}{ Pre-emptive } & Mixed chimerism & $\begin{array}{l}\text { More common indication in } \\
\text { RIC setting } \\
\text { PB mixed myeloid chimerism } \\
\text { predicts molecular and } \\
\text { morphologic relapse better } \\
\text { than CD3+ chimerism and } \\
\text { overall chimerism status } \\
\text { Consider DLI, preferably } \\
\text { escalating dose regimen, in } \\
\text { absence of achievement of full } \\
\text { myeloid chimerism or trend to } \\
\text { loss of full myeloid chimerism }\end{array}$ & $(20,21,54)$ \\
\hline & Presence of MRD & $\begin{array}{c}\text { Directed by MRD or } \\
\text { cytogenetic abnormalities as } \\
\text { discussed above }\end{array}$ & $(20,39,43,44)$ \\
\hline Salvage & $\begin{array}{l}\text { Overt morphological } \\
\text { relapse }\end{array}$ & $\begin{array}{l}\text { Lower rate of CR compared } \\
\text { with pre-emptive strategy }\end{array}$ & $(43,44)$ \\
\hline
\end{tabular}

Table 6: Suggested Indications for DLI approaches in MF Allo-HCT 


\begin{tabular}{|c|c|c|c|c|}
\hline & Donor & $\begin{array}{l}\text { HLA-matched } \\
\text { Sibling/ } \\
\text { unrelated } \\
(10 / 10)\end{array}$ & $\begin{array}{l}\text { HLA-mismatched } \\
\text { unrelated } \\
(9 / 10)\end{array}$ & $\begin{array}{c}\text { Haploidentical } \\
\text { (T-cell replete } \\
\text { haplo-HCT with } \\
\text { PTCy) }\end{array}$ \\
\hline \multirow{2}{*}{$\begin{array}{c}1^{\text {st }} \mathrm{DLI}, \\
\text { (starting dose }{ }^{*} \text { ) }\end{array}$} & Pre-emptive & $5 \times 10^{6} \mathrm{CD}^{+} / \mathrm{Kg}$ & $1 \times 10^{6} \mathrm{CD}^{+} / \mathrm{Kg}$ & $1 \times 10^{5} \mathrm{CD}^{+} / \mathrm{Kg}$ \\
\hline & Salvage & $1 \times 10^{7} \mathrm{CD}^{+} / \mathrm{Kg}$ & $1-5 \times 10^{6} \mathrm{CD}^{+} / \mathrm{Kg}$ & $1 \times 10^{6} \mathrm{CD}^{+} / \mathrm{Kg}$ \\
\hline $\begin{array}{l}\text { Second and } \\
\text { subsequent }\end{array}$ & \multicolumn{4}{|c|}{ Sequential 'Half-log-increase' DLI dose should be given (repeat every 6-8 weeks) } \\
\hline
\end{tabular}

Table 7: Suggested DLI approaches: dosing and scheduling as per donor type, adapted from De Vos et al, 2019 (ref. 55) 
Summary of Recommendations for MF second allo-HCT

The main indication for second allo-HCT is relapsed disease with no response to DLI (or lack of available DLI) or primary/ secondary graft failure. Recipient should have a good performance status to be suitable for second allo-HCT with no major co-morbidities.

Access to funding for second transplants varies between countries

Bridging therapies to second allo-HCT are very patient-specific

No general recommendations can be given

In the absence of a contraindication or donor-specific antibodies, either the original or an alternative donor can be used as outcomes do not appear to differ

Conditioning intensity and the platform of choice depends on recipient age, co-morbidities, the prior conditioning platform and choice of donor Normally these are RIC-based, frequently incorporate ATG, and should be of low toxicity but with a potent 'anti-MF' effect

There is emerging evidence supporting the use of Fludarabine, treosulphan $(36-42 \mathrm{~g} / \mathrm{m} 2)$ and ATG although further evaluation is required(49)

Table 8: Summary of EBMT Recommendations for MF second allo-HCT 
Cytopenias following allo-HCT for MF

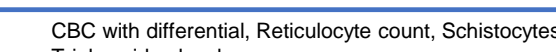

Coagulation screens (PT, PTT)

Creatinine, Transaminases, Serum folate and B12 levels,

PCritin, thyroid function tests, testosterone, LH, FSH levels,

CD3+, CD4+, CD8+, CD56+ cell counts by flow cytometry (PB)

Marrow smear

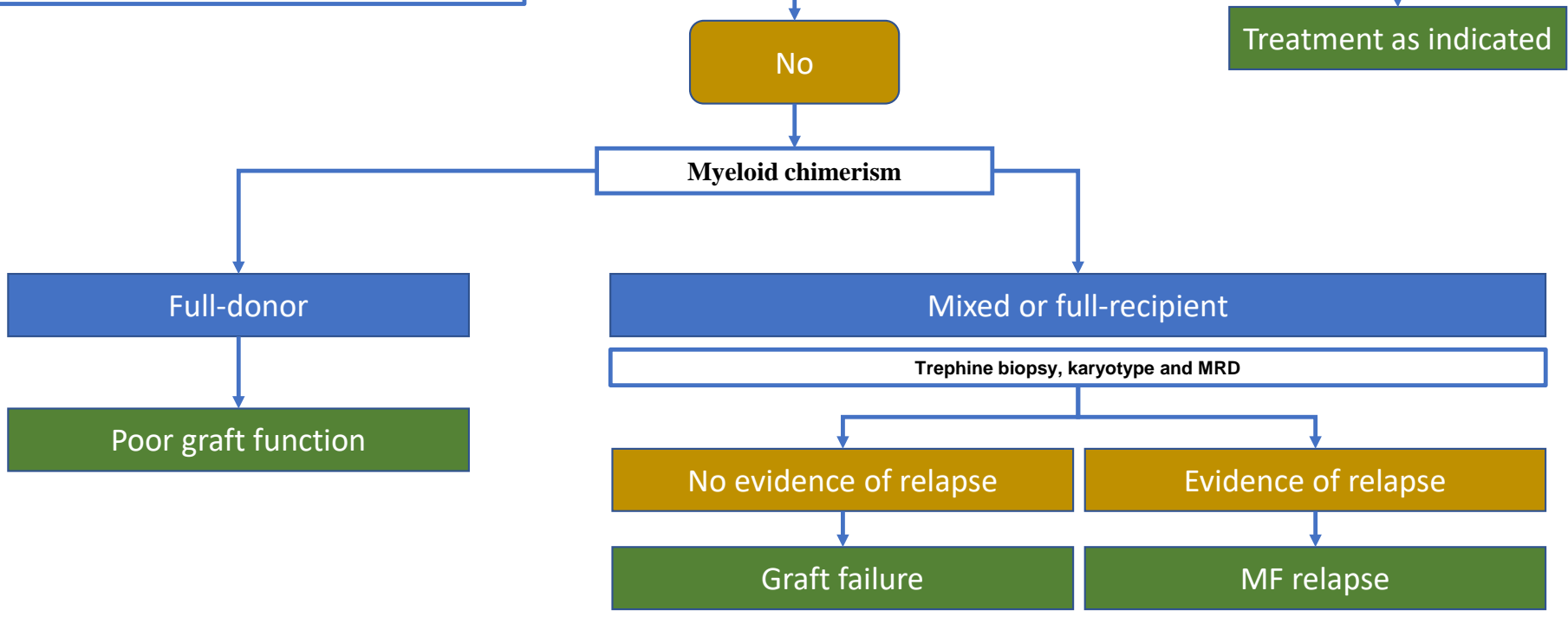

